Article

\title{
Evaluation of Rice Straw Ash as a Pozzolanic Addition in Cementitious Mixtures
}

\author{
Samantha Hidalgo ${ }^{1} \mathbb{D}$, Lourdes Soriano ${ }^{2}$, José Monzó ${ }^{2} \mathbb{D}$, Jordi Payá ${ }^{2} \mathbb{D}$, Alba Font ${ }^{2} \mathbb{D}$ \\ and $\mathrm{M}^{\mathrm{a}}$ Victoria Borrachero ${ }^{2, *}$ \\ 1 Facultad de Ingeniería en Ciencias de la Tierra, Escuela Superior Politécnica del Litoral (ESPOL), \\ 09-01-5863 Guayaquil, Ecuador; shidalgo@espol.edu.ec \\ 2 Grupo de Investigación en Química de los Materiales (GIQUIMA), Instituto de Ciencia y Tecnología del \\ Hormigón (ICITECH), Universitat Politècnica de València (UPV), 46022 Valencia, Spain; \\ lousomar@upvnet.upv.es (L.S.); jmmonzo@cst.upv.es (J.M.); jjpaya@cst.upv.es (J.P.); \\ alprefon@upvnet.upv.es (A.F.) \\ * Correspondence: vborrachero@cst.upv.es
}

Citation: Hidalgo, S.; Soriano, L.;

Monzó, J.; Payá, J.; Font, A.;

Borrachero, M.V. Evaluation of Rice Straw Ash as a Pozzolanic Addition in Cementitious Mixtures. Appl. Sci. 2021, 11, 773. https://doi.org/ 10.3390/app11020773

Received: 30 November 2020 Accepted: 12 January 2021 Published: 15 January 2021

Publisher's Note: MDPI stays neutral with regard to jurisdictional clai$\mathrm{ms}$ in published maps and institutional affiliations.

Copyright: (C) 2021 by the authors. Licensee MDPI, Basel, Switzerland. This article is an open access article distributed under the terms and conditions of the Creative Commons Attribution (CC BY) license (https:// creativecommons.org/licenses/by/ $4.0 /)$.

\begin{abstract}
Rice husk ash is one of the most widely studied biomass ashes used in pozzolanic addition. Given its lower silica content, rice straw ash (RSA) has been explored less often, despite the fact that, according to the United Nations Food and Agriculture Organization (FAO), rice straw (RS) production is estimated at 600 million tons/year. In this work, RSA was physically and chemically characterized, and its pozzolanic properties were assessed. A controlled conditioning, burning, homogenization and grinding procedure was carried out to obtain RSA from RS. Chemical composition, insoluble residue, reactive silica, chloride content and particle size distribution were assessed for ash characterization. To determine RSA pozzolanicity, Frattini, electrical conductivity and $\mathrm{pH}$ measurements in an aqueous suspension of hydrated CH/RSA mixtures were obtained. Portland cement (PC) mortars with 15\% and $30 \%$ RSA substitutions evaluated. The mechanical tests showed specimens with a strength activity index up to $90 \%$ and $80 \%$ with $15 \%$ and $30 \%$ RSA, respectively, after 3 days, and these values grew to $107-109 \%$ after 90 curing days.
\end{abstract}

Keywords: rice straw ash; pozzolan; Frattini test; $\mathrm{pH}$ and conductivity test; thermogravimetry; mechanical strength

\section{Introduction}

One of the most important challenges in the construction industry is to reduce environmental impacts, produced principally by widespread ordinary Portland cement (PC) use, given its associated large carbon footprint. For the production of $1 \mathrm{~kg}$ of PC, approximately $1 \mathrm{~kg}$ of $\mathrm{CO}_{2}$ is emitted [1]. The latest research suggests that around $8 \%$ of global anthropogenic $\mathrm{CO}_{2}$ is due to PC fabrication [2]. The use of Supplementary Materials from industrial waste can contribute to reducing the carbon footprint. The most widely used Supplementary Materials are fly ash (FA), blast furnace slag (BFS), silica fume (SF), among others [3-7]. Given the pozzolanic/hydraulic reactions of these materials in PC mortars and concretes, mechanical behavior and durability properties are enhanced.

Other Supplementary Materials used as substitutions or additions in PC-based mixes are ashes from agricultural waste. In the last few decades, different research groups around the world have studied using such wastes, but their application is still scarce.

Agricultural waste mainly comprises straw (leaves and stems) and fruit shells, while other types include bagasse, cobs, and pod seeds and shells. With proper selection and treatment, this waste can be used as a PC substitute in the manufacture of suitable building materials.

Controlling biomass combustion is key. Biomass is produced in large quantities worldwide. However, due to their ill-defined reuse and poor management in open-air 
combustion or kiln combustion processing treatments, the obtained biomass ashes offer no optimal usage.

Nowadays, much interest is being shown in biomass as a fossil fuel replacement because of its high calorie value [8]. Forecasts of the use of bioenergy indicate that it is likely to increase in the future, but the policy markets of each country complicate predicting its future use [9].

Biomass reuse can be considered a $\mathrm{CO}_{2}$-neutral or quasi-neutral process, as the carbon released to the atmosphere during combustion is previously fixed by the plant during the photosynthetic process. The ash produced in selected cases has pozzolanic properties and can, therefore, be valuable in the construction industry.

Rice straw (RS) is waste from rice production, the annual production of which is 67 million tons worldwide [10]. This waste is difficult to manage, especially in natural environments such as wetlands where it usually develops. In the Albufera Lagoon of Valencia (Spain), around 75,000-90,000 tons of RS are produced every year [11]. Such waste is generated in a very short time and at a given time of the year, and is traditionally subjected to burning in the same cultivation field. Farmers believe that this practice helps to destroy fungal spores, such as Pyricularia oryzae, as well as some bacteria and weed seeds. It also facilitates the re-application of certain nutrients to the soil. However, this practice not only poses serious health problems in the areas surrounding cultivation areas, but also considerable environmental damage. Straw burning is an important gas emitter, with emissions in the form of carbon dioxide $\left(\mathrm{CO}_{2}\right)$, methane $\left(\mathrm{CH}_{4}\right)$, nitrogen oxides $\left(\mathrm{NO}_{\mathrm{x}}\right)$, sulfur oxides $\left(\mathrm{SO}_{\mathrm{x}}\right)$, hydrocarbons, dioxins and particles of different natures. Their possible controlled burning and the valorization of the corresponding ash can be possible solutions to these problems.

Many ashes from agricultural waste have proven their feasibility in the concrete industry as Supplementary Materials in the cement matrix and/or for manufacturing new building materials [12-17].

RS is an agricultural waste formed by leaves, stems and roots composed of fibrous cellulose containing high silica content [18]. Some research works have focused on using RS ash (RSA) as a supplementary component in cements.

Roselló et al. studied ashes from different RS parts and their chemical composition: rice leaf ash (RLA), rice leaf sheath ash (RLSA) and rice stem ash (RSA). $\mathrm{SiO}_{2}$ was the main oxide present in all the ashes, but its content was higher in RSA. Other oxides present in these ashes were $\mathrm{K}_{2} \mathrm{O}$ and $\mathrm{CaO}$ [18]. The microscopic study of RSA revealed that it is heterogeneous in the chemical distribution, depending on the cellular structure that remained after the combustion process [18].

Sung et al. [19] studied concretes with a partial PC replacement with RSA. These authors evaluated different properties, such as density, compressive and flexural strengths, durability (mass loss of concrete immersed in $5 \% \mathrm{H}_{2} \mathrm{SO}_{4}$ during 32 days) and ultrasonic pulse velocity. From the mechanical point of view, the best results were obtained with a concrete containing 5\% RSA, although the durability results were better for the concrete with $15 \%$ RSA.

Munshi et al. [20] studied using RSA as a pozzolanic material in cement mortars, and obtained a $12.5 \%$ increase in compressive strength when substituting $10 \%$ PC for RSA. Introducing RSA did not severely affect setting times. Therefore, these authors concluded that using RSA as a pozzolanic material was satisfactory, and they suggested a study to improve combustion conditions to obtain better quality ash. In a later work, the same authors [21] analyzed the relationship between the permeability and compressive strength of mortar with PC replacements up to $15 \%$, and indicated that permeability decreased with increased compressive strength within the 5-10\% substitution range. At $15 \%$ substitution, compressive strength slightly decreased and permeability increased. They also studied RSA obtained at different temperatures (uncontrolled temperature, 400, 600, and $750{ }^{\circ} \mathrm{C}$ ) [22] and concluded that the best pozzolanic reactivity was obtained by burning biomass at 600 and $750{ }^{\circ} \mathrm{C}$. 
Agwa et al. [23] analyzed the mechanical properties of lightweight self-compacting concrete by incorporating RSA and cotton stalk ash (CSA). They observed diminished workability, improved mechanical strength and greater structure compactness in the PC samples with replacements up to $10 \%$ with both ashes.

Pandey and Kumar [24] studied the effect of replacing PC with RSA, microsilica (MS), and a combination of both materials, to fabricate pavement concrete. They recommended a mixture with 5\% RSA and 7.5\% MS, which led to $53.6 \mathrm{MPa}$ compressive strength after 28 curing days.

This work aims to analyze the reuse, as a pozzolanic material, of the rice straw (RS) collected in the Albufera (Spain) and to study the rice straw ash (RSA) obtained during outdoor burning, with a self-made burner. RSA was characterized by chemical composition and a mineralogical structure. Finally, various techniques were carried out to analyze ash reactivity: (a) standardized Frattini tests and $\mathrm{pH}$ and conductivity measurements for an aqueous suspension of $\mathrm{CH} / \mathrm{RSA}$ mixtures; (b) thermogravimetric tests on PC/RSA pastes and mechanical tests on PC/RSA mortars.

\section{Materials and Method}

The experimental procedure followed in the present research is summarized in Figure 1.

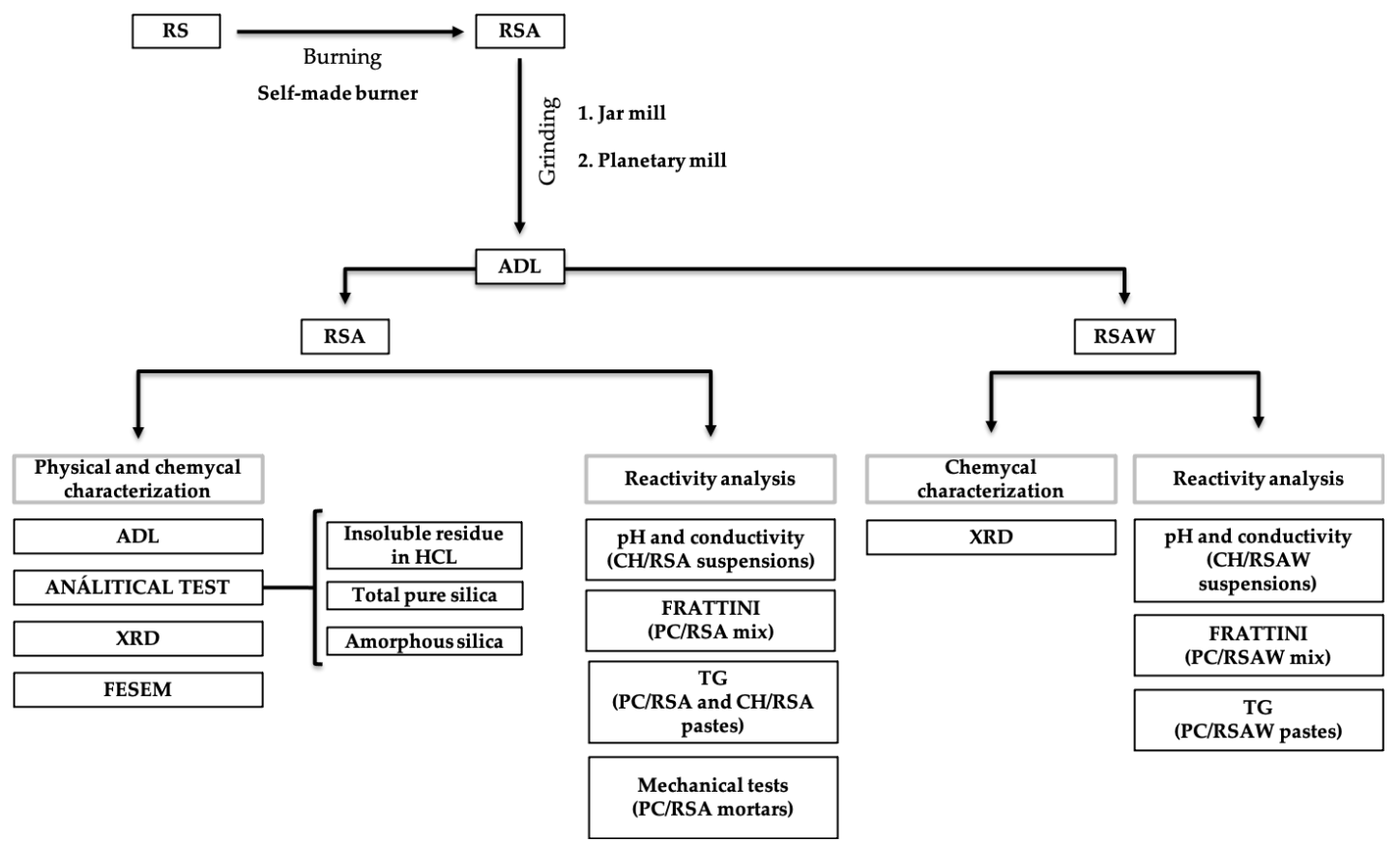

Figure 1. General view of the experimental procedure followed in the present research.

RS was supplied by Banc de Palla (Valencia, Spain) and was burned at the Universitat Politècnica de València (UPV) in a self-made burner (capacity of $3 \mathrm{~m}^{3}$ ), provided with a cover to avoid possible pollution by air agents. The burner (see Figure 2) consists of concrete blocks that form a ring, with holes opening between blocks to supply air during combustion. Two metal plates are placed at a height of $1 \mathrm{~m}$ to accommodate biomass.

RS combustion was rapid and energetic, with about $3 \mathrm{~m}$ flames which reduced after $10 \mathrm{~min}$. The combustion temperature reached while burning biomass came close to $500^{\circ} \mathrm{C}$. Unburned particles were removed by sieving and the obtained ash was homogenized. The calcination temperature is a critical parameter. Low temperatures (under $400{ }^{\circ} \mathrm{C}$ ) may yield ash with many unburned particles, which can give workability problems and low strengths. High calcination temperatures (up $800^{\circ} \mathrm{C}$ ) will yield crystalline components in the ash and therefore with lower reactivity. 


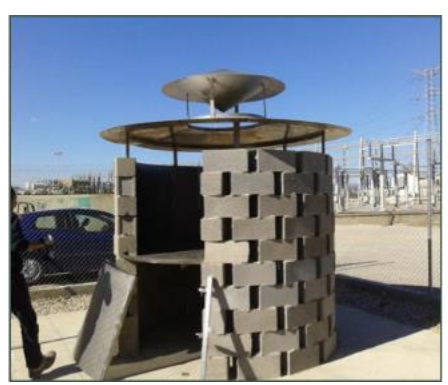

Figure 2. Self-made burner to obtain rice straw ash (RSA).

Two grinding types were carried out to reduce the granulometry of the obtained RSA. First, $500 \mathrm{~g}$ of RSA were milled for $15 \mathrm{~min}$ in a jar mill with 50 large and 60 small alumina balls. The mill was a Gabrielli Roller 1 model. The obtained material had an average particle size of $46.86 \mu \mathrm{m}$. In order to increment the reactivity, the RSA was ground in a model Gabrielli Mill 2 planetary mill with $100 \mathrm{~g}$ of RSA and 80 small alumina balls for $10 \mathrm{~min}$. Malvern Instruments Mastersizer 2000 equipment was used for the particle size analysis.

Lime $\left(\mathrm{Ca}(\mathrm{OH})_{2}\right)$, called $\mathrm{CH}$ in the present paper, was supplied by Panreac S.A $(95 \%$ purity) and PC type CEM I-52.5 R was supplied by Lafarge-Spain. Sand was provided by Sílices Carrión Martínez S.L (Llíria-Spain).

\subsection{Physical and Chemical Characterization of RSA}

A sequential X-ray spectrometer, model PHILPS MAGIX PRO, equipped with a rhodium tube and a beryllium window, was employed for the chemical composition determination (X-ray fluorescence, $\mathrm{XRF}$ ).

The insoluble residue was determined by obtaining the total silica and alumina proportion, and subsequently determining the content of the crystalline and amorphous silica phases [25]. Then, $1 \mathrm{~g}$ of RSA was weighed and $75 \mathrm{~mL}$ of $\mathrm{HCl} 3 \mathrm{M}$ were added. The mixture was stirred and placed on a heating plate at $250{ }^{\circ} \mathrm{C}$. It was left to boil for $15 \mathrm{~min}$. The mixture was gravimetrically filtered by a tapered funnel with paper filter. The precipitate was repeatedly washed with hot deionized water until filtration was free of chlorides. The final clean precipitate was burned with a Bunsen burner and finally calcined in a muffle at $900{ }^{\circ} \mathrm{C}$ for $1 \mathrm{~h}$. The obtained solid contained both crystalline and amorphous silica.

After establishing the insoluble residue weight in $\mathrm{HCl}$ (or impure silica), it was moistened with a few drops of distilled water and two drops of concentrated $\mathrm{H}_{2} \mathrm{SO}_{4}$. Next, $5 \mathrm{~mL}$ of concentrated HF was poured to remove silica by volatilization and the crucible was placed on a heating plate at $250{ }^{\circ} \mathrm{C}$ until total liquid evaporation. The remaining solid was calcined at $950^{\circ} \mathrm{C}$ for $1 \mathrm{~h}$. Total pure silica was calculated as the difference between the weight of the insoluble residue and that obtained after this second calcination.

To determine the amorphous or reactive silica content, $1 \mathrm{~g}$ of RSA was taken and the above-described acid-attack process was repeated to leave the sample free of chlorides. Then, $100 \mathrm{~mL}$ of $\mathrm{KOH}$ was added and placed inside a spherical flask. When boiling started, the paper filter was placed into the flask and left to boil for $3 \mathrm{~min}$. The suspension was filtered through filter paper. The retained solid, which contained crystalline silica, was washed with hot deionized water and $100 \mathrm{~mL}$ of $\mathrm{HCl} 0.1 \mathrm{M}$. The chloride-free solid was calcined and weight was recorded. The procedure explained above, using distilled water, $\mathrm{H}_{2} \mathrm{SO}_{4}$ and $\mathrm{HF}$ additions, was carried out for the crystalline silica content determination. The difference between total silica and crystalline silica content was the quantity of the amorphous or reactive silica present in RSA.

The used X-ray diffractometer was a Bruker AXS D8 Advance model. The intensity and voltage of the X-ray generator tube were adjusted to $20 \mathrm{~mA}$ and $40 \mathrm{KV}$, respectively. Diffractograms were recorded for the interval $2 \theta$ between 5 and 70 degrees, with a pitch an- 
gle of 0.02 and an accumulation time of $2 \mathrm{~s}$. The employed equipment for the field emission scanning microscopy (FESEM) was the ultra 55 model of ZEISS OXFORD instruments.

\subsection{Analysis of RSA Reactivity}

$\mathrm{pH}$ and electrical conductivity were assessed following the proposed methodology by Tashima et al. [26], consisting of monitoring CH/RSA aqueous suspensions in different proportions at a certain temperature for 7 days. For a given reaction time, lowering electrical conductivity and $\mathrm{pH}$ values indicate the RSA pozzolanic reaction taking place and, thus, the unsaturation of the solution in relation to calcium hydroxide. Different $\mathrm{CH} / \mathrm{RSA}$ proportions were evaluated: $1 / 9,2 / 8,3 / 7,4 / 6$ and $5 / 5$. To prepare suspensions, $50 \mathrm{~mL}$ of deionized water were placed inside a $100 \mathrm{~mL}$ Erlenmeyer flask, which was tightly closed and placed into thermostatic bath at $60^{\circ} \mathrm{C}$. Then $\mathrm{CH}$ was added and the suspension was maintained at $60^{\circ} \mathrm{C}$ with shaking until the test dates. At this time, the electrical conductivity and $\mathrm{pH}$ values were measured (control values), and RSA was added. The sum of RSA and $\mathrm{CH}$ was $1 \mathrm{~g}$. Data were collected for 7 days every $24 \mathrm{~h}$. The employed instruments were a pH-meter Crison micropH2001 and a conductivity-meter Crison microCM2201.

The Frattini pozzolanicity test was carried out in accordance with UNE EN 196-5 [27]. The procedure consisted of: (a) preparing $20 \mathrm{~g}$ of the PC/RSA mixture at 90/10, 80/20 and $75 / 25$ mass ratios and adding $100 \mathrm{~mL}$ of distilled water; (b) keeping the mixture at $40{ }^{\circ} \mathrm{C}$ for 8 days in hermetically sealed polyethylene bottles; and (c) filtration through filter paper. The hydroxide ions $\left(\mathrm{OH}^{-}\right)$contained in the filtrate were titrated with a diluted $10^{-1} \mathrm{~mol} \cdot \mathrm{L}^{-1}$ hydrochloric acid solution using methyl orange as an indicator. Calcium ions $\left(\mathrm{Ca}^{2+}\right)$ were titrated by $0.03 \mathrm{~mol} \cdot \mathrm{L}^{-1}$ ethylenediaminetetraacetic acid (EDTA) solution using calcon as an indicator. The results were drawn in a graph indicating the concentration of $\mathrm{Ca}^{2+}$ ions (in $\mathrm{mmol} \cdot \mathrm{L}^{-1}$ ) vs. the concentration of $\mathrm{OH}^{-}$ion (in $\mathrm{mmol} \cdot \mathrm{L}^{-1}$ ) [28].

For the thermogravimetric analysis (TG/DTG), the $1 / 3$ and $1 / 1$ proportions of $\mathrm{CH} / \mathrm{RSA}$ pastes were prepared and studied at $3,7,28$ and 90 curing days at $20^{\circ} \mathrm{C}$. The control PC samples and PC/RSA pastes were also analyzed in the proportions of $7 / 3$, $7.5 / 2.5,8 / 2$ and 8.5/1.5 with a water/binder ratio of 0.5 , and were studied for the same curing ages as the $\mathrm{CH} / \mathrm{RSA}$ mixtures. Samples were tested within a temperature range from 35 to $600{ }^{\circ} \mathrm{C}$ using aluminum sealed crucibles in a nitrogen atmosphere. The used equipment was Mettler Toledo a TGA 850 module.

Given the high chloride content in RSA (see Table 1, and for the $\mathrm{pH}$ and electrical conductivity, Frattini and thermogravimetry tests, a sample washed with hot deionized water was analyzed to check their influence on reactivity. This sample was named RSAW.

Table 1. Doses of the control and PC/RSA mortars.

\begin{tabular}{ccccc}
\hline Mortar & PC $(\mathbf{g})$ & RSA $(\mathbf{g})$ & Water $(\mathbf{g})$ & Sand $(\mathbf{g})$ \\
\hline Control & 450.0 & - & 225.0 & 1350.0 \\
RSA 15\% & 382.5 & 67.5 & 225.0 & 1350.0 \\
RSA 30\% & 315.0 & 135.0 & 225.0 & 1350.0 \\
\hline
\end{tabular}

The influence of replacing RSA in PC mortars on flexural and compressive strength development was studied on $40 \times 40 \times 160 \mathrm{~mm}^{3}$ prismatic specimens at two replacement percentages: $15 \%$ and $30 \%$. The water/binder used was 0.5 and the sand/binder ratio was 3. The employed dose is detailed in Table 1.

\section{Results}

\subsection{Physical and Chemical Characterization of RSA}

The particle size distribution of RSA after two grinding procedures is seen in Figure 3. The mean particle diameter was $13.3 \mu \mathrm{m}$ after the second grinding, which is appropriate to obtain good performance pozzolan [29]. 


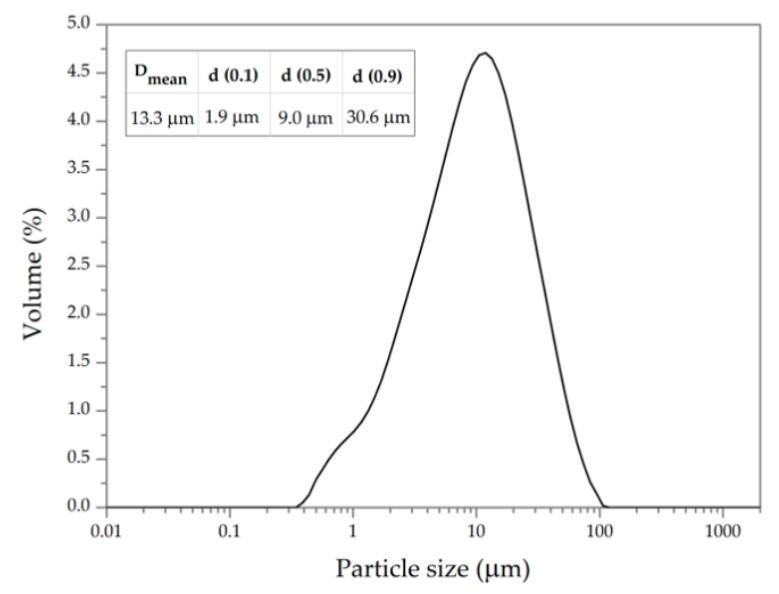

Figure 3. Particle size distribution of RSA.

The chemical composition of RSA is summarized in Table 2. The main oxides in the ash were $\mathrm{SiO}_{2}$ and $\mathrm{K}_{2} \mathrm{O}$. The material had a high loss of ignition percentage $(14.6 \%)$, which is possibly attributed to the presence of unburned particles and carbonates. Chloride content was high $(3.5 \%)$, which should be taken into account for certain uses as a PC substitute (not recommended for steel-reinforced concrete because of the potential activation of metal corrosion). The high quantity of alkali compounds should be taken into account when reactive aggregates are used to avoid dangerous aggregate-alkali reactions; however, the studied residue (RS) was locally produced from the Albufera (Valencia, Spain) for its near geographical zones application and this type of aggregate is not usually used in this area.

Table 2. Chemical composition (wt \%) of RSA (X-ray fluorescence (XRF) analysis).

\begin{tabular}{ccccccccccccc}
\hline$\%$ & $\mathrm{SiO}_{2}$ & $\mathrm{Al}_{2} \mathbf{O}_{3}$ & $\mathrm{Fe}_{2} \mathbf{O}_{3}$ & $\mathrm{CaO}$ & $\mathbf{M g O}$ & $\mathbf{S O}_{3}$ & $\mathbf{K}_{2} \mathbf{O}$ & $\mathbf{N a}_{2} \mathbf{O}$ & $\mathbf{P}_{2} \mathbf{O}_{5}$ & $\mathbf{C l}^{-}$ & Other & L.O.I \\
\hline RSA & 52.44 & 0.47 & 0.17 & 8.01 & 2.71 & 2.26 & 12.05 & 0.89 & 2.58 & 3.52 & 0.29 & 14.60 \\
\hline
\end{tabular}

The obtained insoluble waste was $63.1 \%$ and total silica was $56.8 \%$. This last value differed from that obtained by the XRF analysis, which can be attributed to differences in the analytical method because of its distinct filtration and calcination processes. The percentage of amorphous silica was $51.8 \%$, which is very high compared to that of rice husk ash (RHA) analyzed by Bouzón et al. [25] ( $85 \%$ of total $\mathrm{SiO}_{2}$ and $31.5 \%$ amorphous silica). This means that more than $90 \%$ of the silica in RSA is in an amorphous state, which is a good indicator of its potential pozzolanic activity.

In Figure 4, the XRD diffractograms of RSA and RSAW are represented. For RSA, the main phase was silvine ( $\mathrm{KCl}$, PDFCard \#411476) according to the marked presence of chloride. There were also two crystalline compounds associated with silica: quartz $\left(\mathrm{SiO}_{2}\right.$,

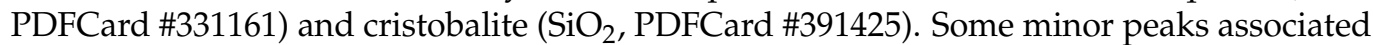
with the crystalline phases of arkanite $\left(\mathrm{K}_{2} \mathrm{SO}_{4}, \mathrm{PDFCard} \# 050613\right)$ and calcite $\left(\mathrm{CaCO}_{3}\right.$, PDFCard \#050586) were observed. The baseline deviation fell within the $2 \Theta=18^{\circ}-37^{\circ}$ range, which was attributed to the amorphous phase [25]. 

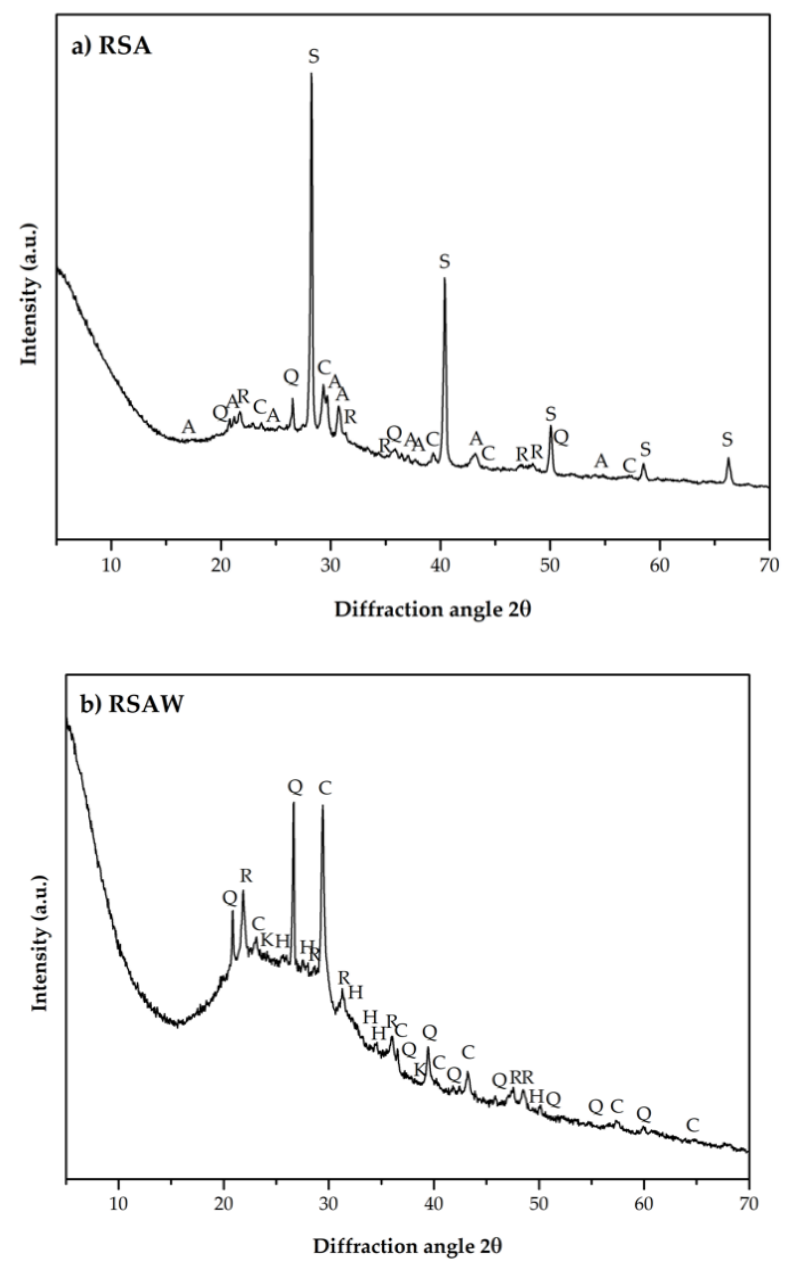

Figure 4. XRD diffractograms: (a) RSA and (b) washed RSA (RSAW).

For the diffractogram of RSAW (Figure 4b), compared to RSA (Figure 4a), the silvine peak decreased and the baseline deviation significantly increased. A new peak also corresponded to hydroxyl chlorinated apatite $\left(\mathrm{Ca}_{5}\left(\mathrm{PO}_{4}\right)_{3}(\mathrm{OH}, \mathrm{Cl})\right.$, PDFCard \#250166). This peak was masked before in the unwashed ash because of the high-intensity silvine peak. The low height value of the peaks vs. the baseline deviation confirmed the main amorphous nature of ash, which agrees with $51 \%$ amorphous silica.

To analyze the effectiveness of the washing process, the soluble chloride contents in the original and washed samples were determined: $4.7 \% \mathrm{Cl}$ appeared in the original RSA, which is far removed from the required value according to Standard UNE-EN 450-1 [30] $(0.1 \% \mathrm{Cl})$ for using fly ash pozzolan in cement. The washed RSA had $0.25 \% \mathrm{Cl}$, which confirmed the effectiveness of the hot water washing process and the significant reduction in the main silvine peak in the XRD diffractogram.

In order to study the particle morphology of RSA, the original and milled ashes were compared by a FESEM analysis (Figure 5). Phytolits were present in the original RSA (Figure 5a). These particles are solid deposits rich in silica [18]. When RSA was milled, the original morphology disappeared and a powdery material appeared (Figure $5 b$ ) with very irregular particles in both shape and porous structure terms. 

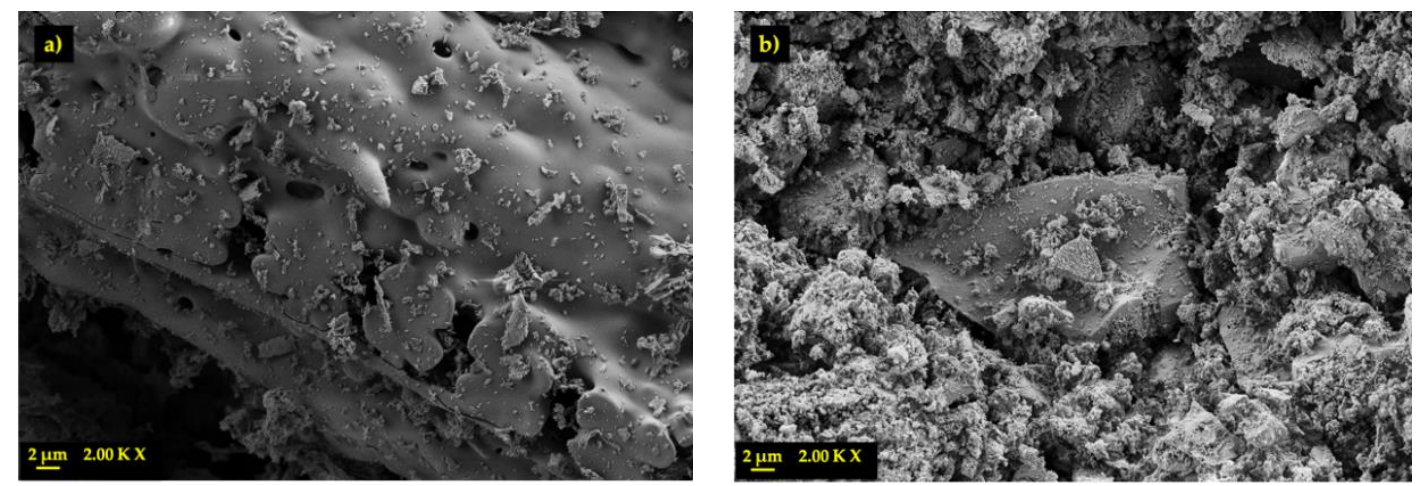

Figure 5. FESEM micrographs of RSA: (a) original; (b) milled.

\subsection{Analysis of RSA Reactivity}

3.2.1. $\mathrm{pH}$ and Electrical Conductivity Studies

Figure 6 depicts the obtained $\mathrm{pH}$ results for both ash types, RSA and RSAW. For the pozzolanic activity assessment, $\mathrm{pH}$ values are represented as the hydroxyl ions $\mathrm{OH}^{-}$concentration. The relative terms $\left(\left[\mathrm{OH}^{\circ}\right]_{\mathrm{i}} /\left[\mathrm{OH}^{-}\right]_{\mathrm{o}}\right)$ were represented as follows (Equation (1)):

$$
\begin{gathered}
\mathrm{pH}+\mathrm{pOH}=14 \\
\mathrm{pOH}=-\log \left[\mathrm{OH}^{-}\right]
\end{gathered}
$$

where:

$\left[\mathrm{OH}^{-}\right]_{\mathrm{i}}$ : hydroxyl ion at a given time $\mathrm{i}$

$\left[\mathrm{OH}^{-}\right]_{\mathrm{o}}$ : initial hydroxyl ion at time 0 immediately after homogenisation

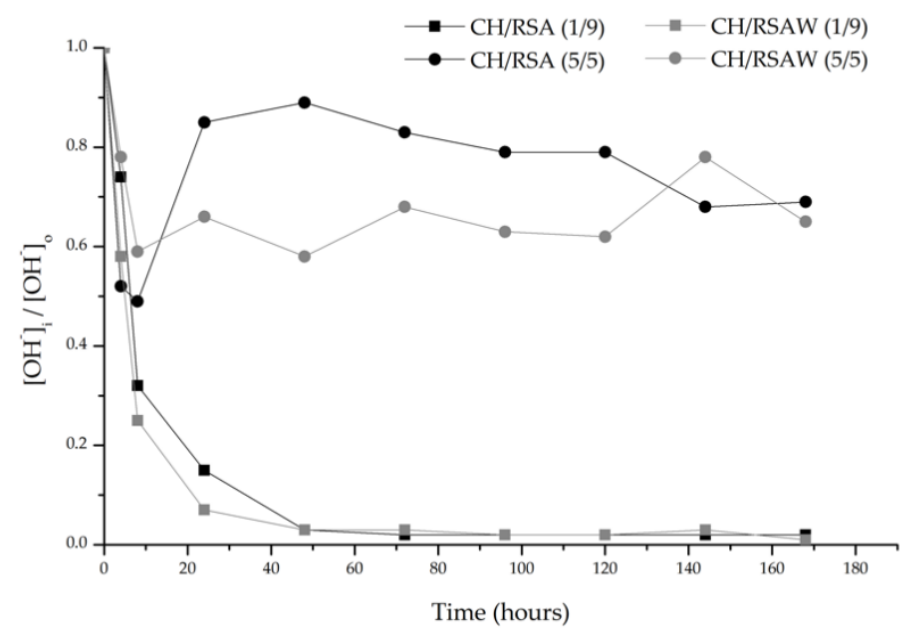

Figure 6. Hydroxyl ion consumption in relative RSA and RSAW terms.

To compare the behavior of ashes, the selected $\mathrm{CH} / \mathrm{RSA}$ suspensions are the extremes of $1 / 9$ and $5 / 5$. As we can observe, both ash types (RSA and RSAW) display the same $\mathrm{pH}$ evolution. For the $1 / 9$ solutions, the behavior is characterized by $\mathrm{CH}$ barely being present. However for the 5/5 solution, the hydroxyl ion significantly increments $24 \mathrm{~h}$ before it stabilizes. This initial increment can be associated with ash soluble salts. The $\mathrm{OH}^{-}$ consumption started after $48 \mathrm{~h}$.

The methodology proposed by Tashima et al. [26] establishes that conductivity loss greater than $30 \%$ was a criterion ( $\mathrm{Lc}>30 \%$ ), and indicates that aqueous solutions are unsaturated in relation to calcium hydroxide. When assessing the results obtained from the loss of conductivity, modifying the method was proposed. 
The RSA employed in the present research contains many soluble chlorides among other elements, which possibly influenced measurements. For this reason, we decided to modify the definitions and criterion proposed by Tashima et al. for $\mathrm{pH}$ and the conductivity analysis [26]. Herein, the proposed definition of the conductivity value for the $\mathrm{CH} / \mathrm{RSA}$ mix for time ( $t$ ) is as follows (Equation (2)):

$$
\left.\mathrm{C}_{\mathrm{i}}=\left(\left(\mathrm{C}_{\mathrm{t}}-\mathrm{C}_{\mathrm{RSA}} * \% \mathrm{RSA}\right) / \mathrm{C}_{\mathrm{t}}\right) * 100\right)
$$

where:

$\mathrm{C}_{\mathrm{i}}$ is the corrected electrical conductivity value for a given time ( $\mathrm{t}$ )

$\mathrm{C}_{t}$ is the electrical conductivity in the CH/RSA aqueous suspension measured for $t$ hours $\mathrm{C}_{\mathrm{RSA}}$ is the electrical conductivity of RSA in water for a given time ( $\mathrm{t}$ ) $\%$ RSA is the percentage of RSA in CH/RSA

In Figure 7, losses of the electrical conductivity curves for all the mixtures prepared with RSA and RSAW are found.
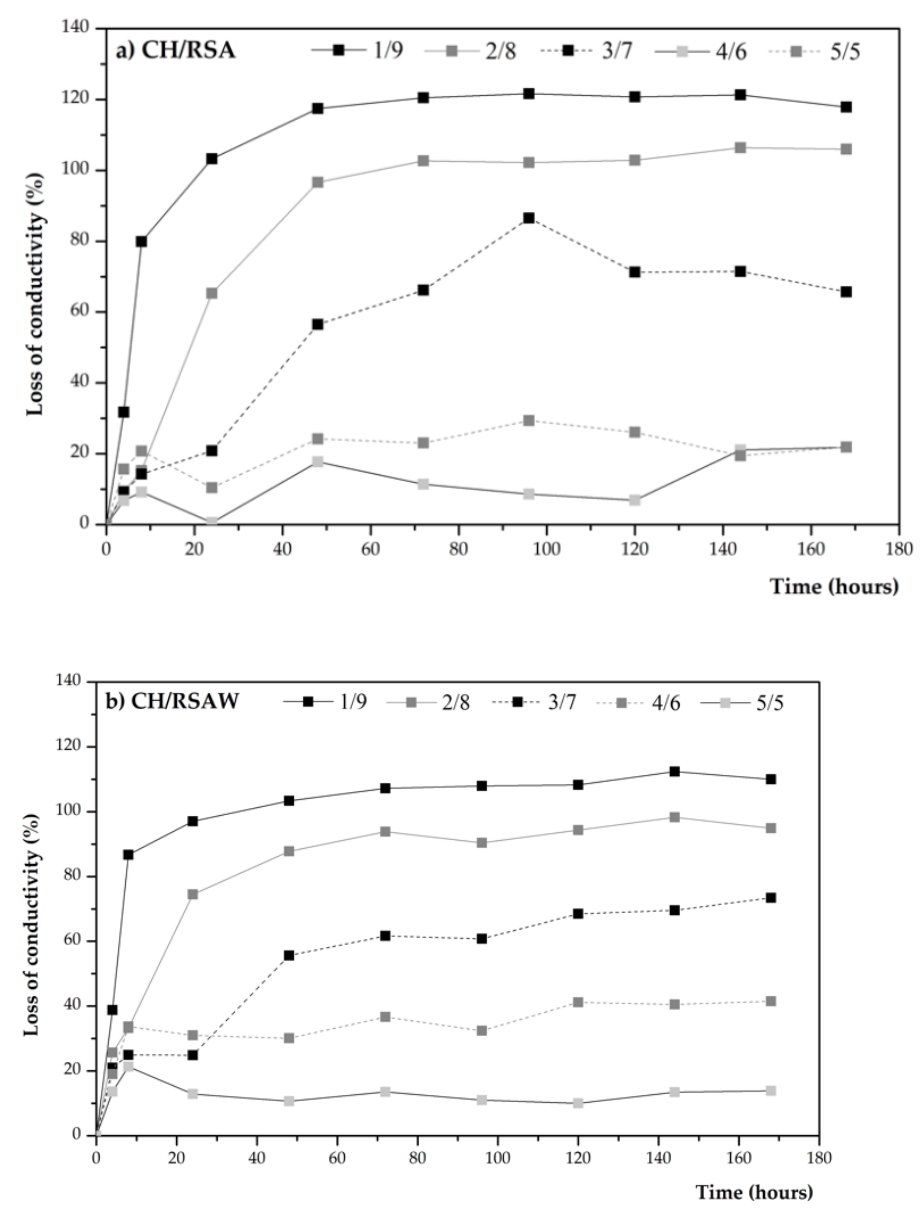

Figure 7. Loss of conductivity versus time tested at $60^{\circ} \mathrm{C}$ : (a) lime/rice straw ash (CH/RSA) mixtures; (b) $\mathrm{CH} / \mathrm{RSAW}$ mixtures.

As seen in Figure 7a for RSA, the loss of conductivity criterion exceeding 30\% is met by mixtures $\mathrm{CH} / \mathrm{RSA}$ of $1 / 9,2 / 8$ and $3 / 7$. According to the classification proposed by Tashima et al. [26], the pozzolanic reactivity shown by RSA was low.

The washing process enhanced RSA reactivity (Figure $7 \mathrm{~b}$ ) and mixture $\mathrm{CH} / \mathrm{RSAW}$ $4 / 6$ met the loss of conductivity criterion. In this case, RSAW can be classified as a pozzolan with medium reactivity. 


\subsubsection{Frattini Test}

Table 3 shows the data obtained by the Frattini test of the studied PC/RSA and PC/RSAW mixtures (replacements of $10 \%, 20 \%$ and $25 \%$, at 8 and 15 days.

Table 3. Results obtained in the Frattini test of Portland cement/rich straw ash (PC/RSA) and PC/RSAW after 8 and 15 days.

\begin{tabular}{cccc}
\hline Sample & Percentage of Replacement (\%) & 8 Days & 15 Days \\
\hline \multirow{3}{*}{ PC/RSA } & $10 \%$ & Negative & Negative \\
& $20 \%$ & Positive & Positive \\
& $25 \%$ & Positive & Positive \\
\hline \multirow{2}{*}{ PC/RSAW } & $10 \%$ & Negative & Negative \\
& $20 \%$ & Positive & Positive \\
& $25 \%$ & Positive & Positive \\
\hline
\end{tabular}

The data confirmed that RSA presented pozzolanic activity and complies with the Frattini test for all the studied percentages, except for $10 \%$ RSA at both 8 and 15 days.

After the washing treatment, (PC/RSAW) the results were similar. The sample with $10 \%$ washed ash still brought about a negative Frattini test as, apparently, there was no positive effect. However, this washing method has already been used to improve pozzolanic reactivity. Kubiliute et al. [31] followed this washing method with mineral wool manufacturing waste, cupola dust, and Chen et al. [32] removed chlorides using this washing process applied with municipal solid waste incineration fly ash.

Figure 8 offers these data at 8 days versus those obtained by other pozzolans: RHA and SF. As observed, these pozzolans presented positive tests for $10 \%$ which can be attributed to the higher amorphous silica content in ash vs. RSA [33,34].

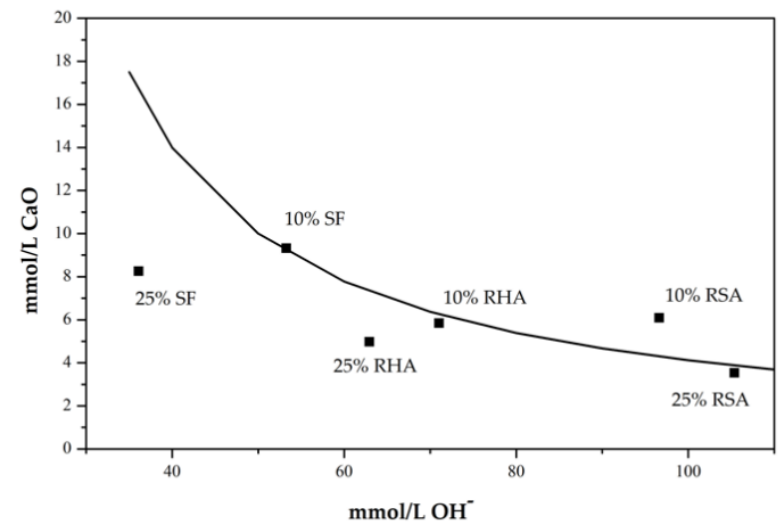

Figure 8. Comparison results of Frattini test for RSA, rice husk ash (RHA) and SF at 10\% and 25\% after 8 days.

Roselló et al. [18] ran a Frattini test with an RSA sample, and reported positive results for 8 days for those samples with $10 \%$ and $25 \%$ ash. This behavior was attributed to the method followed to prepare ash: in this case, controlled muffle burning at $650{ }^{\circ} \mathrm{C}$ of a small biomass sample was carried out, while ash was herein obtained from uncontrolled burning in large quantities. The high temperature reached (crystallizing a small part of silica) and the significant LOI percentage $(14.6 \%)$ led to a moderate decrease in ash reactivity.

\subsubsection{Thermogravimetry Analysis}

Figure 9 represents the derivatives curves (DTG) for the $1 / 3$ and $1 / 1 \mathrm{CH} / \mathrm{RSA}$ pastes after $3,7,28$ and 90 curing days. The presence of a wide peak within the $100-250{ }^{\circ} \mathrm{C}$ range is observed, mainly due to the formation of hydrated calcium silicates (CSH) by the pozzolanic reaction. A peak within the $520-580{ }^{\circ} \mathrm{C}$ temperature range can be attributed to 
the dehydroxylation reaction of the unreacted portlandite $(\mathrm{CH})$. The fixed $\mathrm{CH}$ percentage was calculated with this mass loss according to the following equation (Equation (3)) [35]:

$$
\text { Fixed } \mathrm{CH}(\%)=\frac{\mathrm{CHo}-\mathrm{CH}, t}{\mathrm{CHo}} \times 100
$$

where:

$\mathrm{CH}_{0}$ is the initial quantity of $\mathrm{CH}$ in paste $\mathrm{CH} / \mathrm{RSA}$

$\mathrm{CH}_{p, t}$ is the quantity of $\mathrm{CH}$ present in paste $\mathrm{CH} / \mathrm{RSA}$ after a given reaction time $(t)$
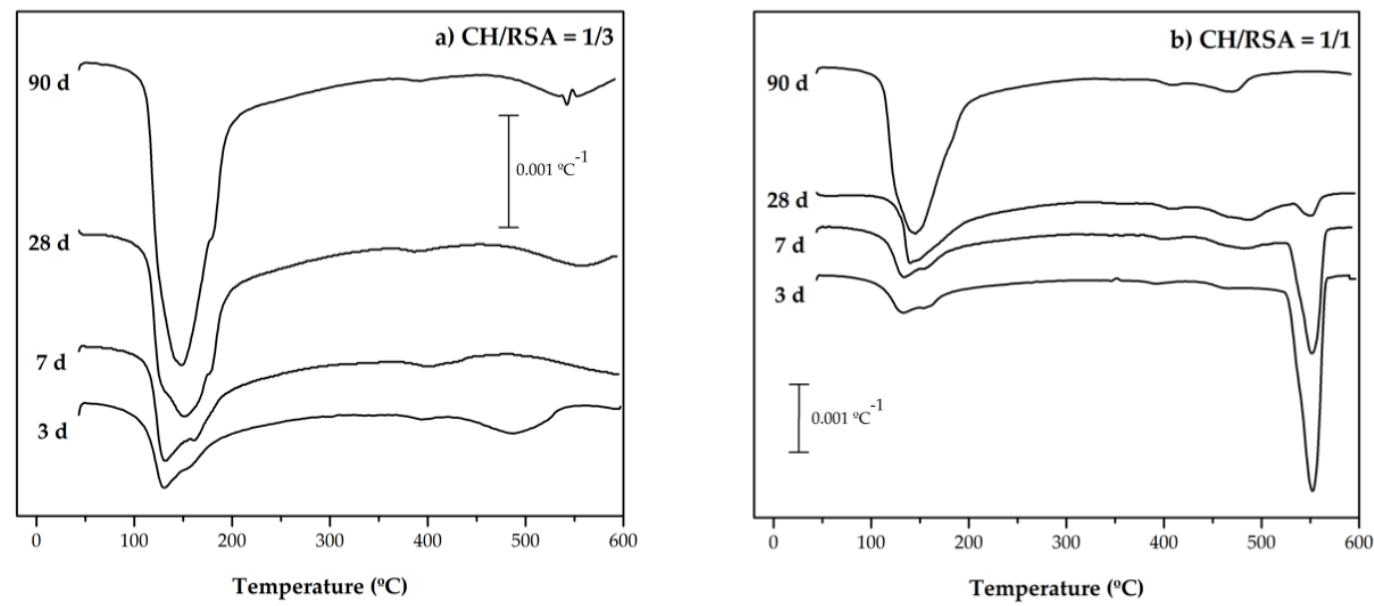

Figure 9. DTG curves for pastes $\mathrm{CH} / \mathrm{RSA}$ : (a) 1/3 paste; (b) 1/1 paste.

In the mixtures with the highest RSA proportion (1/3, Figure 9a) after 7 curing days, all the $\mathrm{CH}$ present in the paste reacted. The pozzolanic reaction was fast and most reaction products occurred on the first 7 hydration days. This has already been reported for other pozzolanic materials, such as the spent fluid catalytic cracking residue (FCC) [35].

For the paste with the lowest RSA proportion (1/1, Figure 9b), a large part of $\mathrm{CH}$ remained unreacted after 7 curing days, and $\mathrm{CH}$ was completely consumed only after 90 days. At this age, an intense peak within the $100-250{ }^{\circ} \mathrm{C}$ range was observed, which indicated the presence of many pozzolanic CSH-type products. This fact has also been found for other pastes made with RSA: in order to quantify the RSA reactivity of the studied pastes $\mathrm{CH} / \mathrm{RSA}$ at a proportion 1/1, Roselló et al. [18] determined the mass loss attributed to portlandite decomposition, and obtained values of $2.15 \%$ and $1.63 \%$ for 7 and 28 days, respectively. In the present research, mass losses were similar, $3.95 \%$ and $0.42 \%$, despite the biomass being burned under uncontrolled conditions.

The $\mathrm{CH} / \mathrm{RSAW}$ pastes were manufactured in the same proportions $(1 / 1$ and $1 / 3)$ and TG/DTG analyses were carried out at 7 and 28 days. In this case, the percentage of fixed $\mathrm{CH}$ was lower, mainly at an early age (Figure 10). One possible explanation could be that soluble salts (sulfates and chlorides) activated the dissolution of portlandite and enhance the pozzolanic reaction rate. Payá et al. [35] stated that, in the presence of compounds such as calcium chloride or sodium sulfate, the pozzolanic reaction would be enhanced.

To clarify the behavior of the washed ash, an XRD analysis was carried out by comparing pastes $1 / 1$ at 28 days with RSA and RSAW. The obtained diffractograms are shown in Figure 11 and the identified mineral phases are summarized in Table 4. The fundamental difference lies in the paste with untreated RSA, where the minerals related to sulfates (arkanite) and chlorides (silvine) were detected, while these minerals were not identified in the sample with the washed ash. 


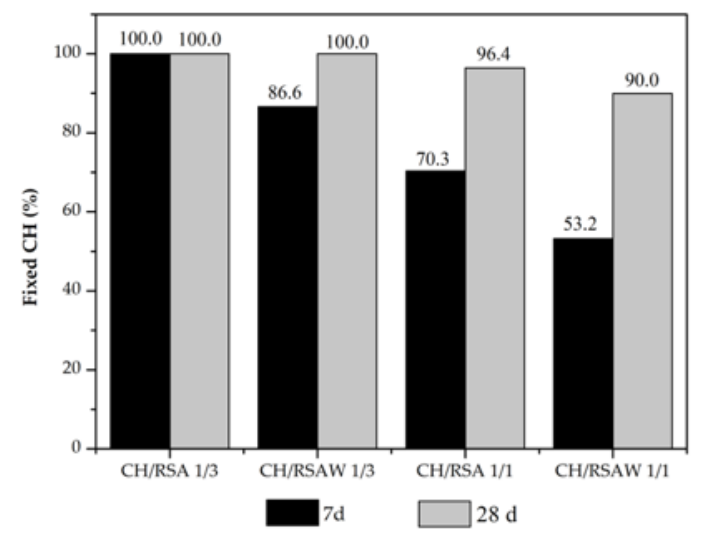

Figure 10. Percentages of fixed $\mathrm{CH}$ for pastes $\mathrm{CH} / \mathrm{RSA}$ and $\mathrm{CH} / \mathrm{RSAW}$.
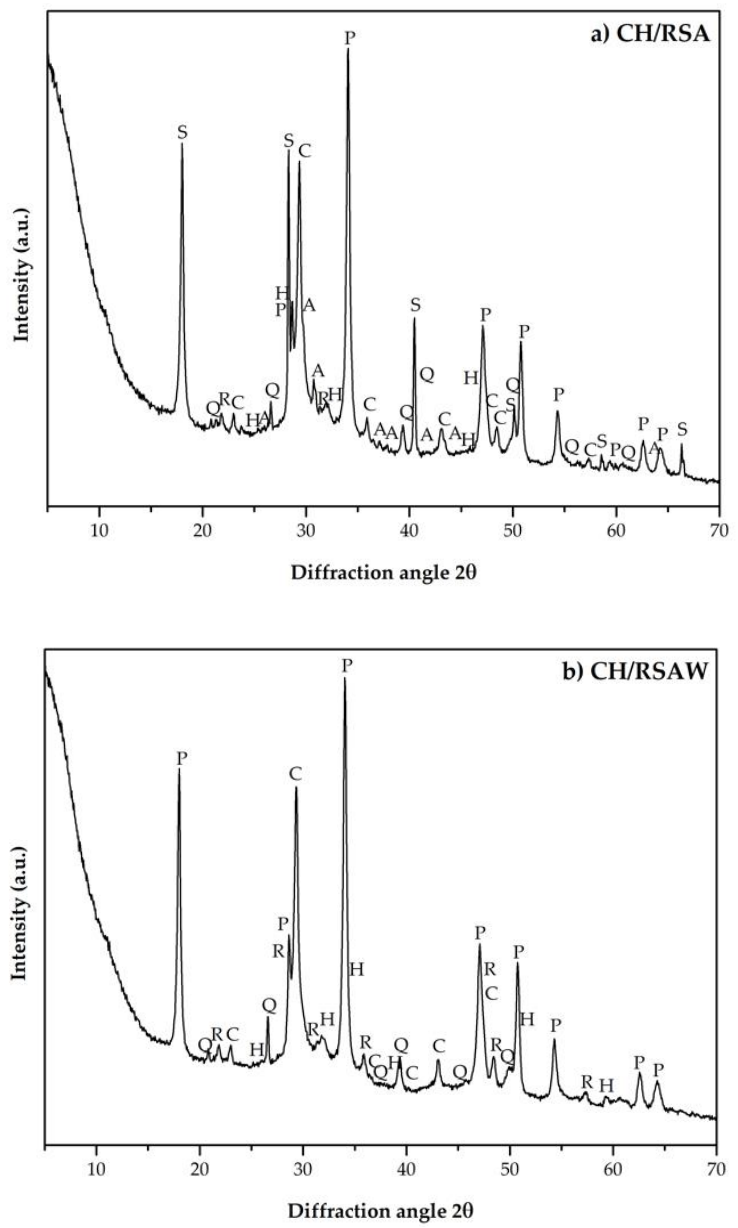

Figure 11. X-ray diffractograms of pastes $1 / 1$ after 28 curing days: (a) $\mathrm{CH} / \mathrm{RSA}$; (b) $\mathrm{CH} / \mathrm{RSAW}$. 
Table 4. XRD characterization: name of minerals, PDF card of phases and chemical formula of phases presented in $\mathrm{CH} / \mathrm{RSA}$ and $\mathrm{CH} / \mathrm{RSAW}$ pastes.

\begin{tabular}{cccc}
\hline Key & Mineral Phase & Chemical Formula & PDFcard \\
\hline$Q$ & Quartz & $\mathrm{SiO}_{2}$ & 331161 \\
\hline $\mathrm{R}$ & Cristobalite & $\mathrm{SiO}_{2}$ & 391425 \\
\hline $\mathrm{C}$ & Calcite & $\mathrm{CaCO}_{3}$ & 050586 \\
\hline $\mathrm{A}$ & Arkanite & $\mathrm{K}_{2} \mathrm{SO}_{4}$ & 050613 \\
\hline$P$ & Portlandite & $\mathrm{Ca}(\mathrm{OH})_{2}$ & 040733 \\
\hline $\mathrm{H}$ & Hydrotalcite & $\mathrm{Mg}_{6} \mathrm{Al}_{2} \mathrm{CO}_{3}(\mathrm{OH})_{16} \cdot 4 \mathrm{H}_{2} \mathrm{O}$ & 140191 \\
\hline $\mathrm{S}$ & Hydrated potassium carbonate & $\mathrm{K}_{2} \mathrm{CO}_{3} \cdot 1.5 \mathrm{H}_{2} \mathrm{O}$ & 110655 \\
\hline
\end{tabular}

A similar thermogravimetric study was carried out on the cement pastes. In order to calculate the percentage of fixed $\mathrm{CH}$ in these pastes, a control cement paste was characterized for each curing age. The fixed $\mathrm{CH}$ was calculated according to the following equation (Equation (4)) [36]:

$$
\text { Fixed } \mathrm{CH}(\%)=\frac{\mathrm{CHc} * \% \mathrm{C}-\mathrm{CHp}}{\mathrm{CHc} * \% \mathrm{C}} \times 100
$$

where:

$\mathrm{CH}_{\mathrm{C}}$ is the amount of portlandite present in the control paste for time $\mathrm{t}$

$\mathrm{CH}_{p}$ is the amount of portlandite present in the paste with RSA for time $t$

$\% C$ is the proportion of RSA present in the paste (e.g., 0.7 is for a PC/RSA paste with a $7 / 3$ mass ratio

The fixed $\mathrm{CH}$ values are summarized in Table 5. The expected trend was generally observed: a rising fixed $\mathrm{CH}$ percentage for the same paste with curing time. After 28 curing days, the fixed $\mathrm{CH}$ for $7 / 3$ paste was $81.5 \%$, and this parameter decreased as the replacing percentage lowered. This behavior is common for reactive pozzolanic materials: for $7 / 3$ paste, the amount of portlandite formed in the hydration of PC was the lowest among the tested pastes, because it had the lowest proportion of PC; additionally, this paste had the highest percentage of RSA, which means that a higher amount of reactive material can be pozzolanically combined with portlandite. Then, the proportion of the fixed $\mathrm{CH}$ was highest for the $7 / 3$ paste; this parameter decreased sequentially for pastes $7.5 / 2.5,8 / 2$ and $8.5 / 1.5$, for which the fixed $\mathrm{CH}$ percentages were $69.5 \%, 61.1 \%$ and $49.8 \%$ respectively. It can be concluded that RSA pozzolanic reactivity was good, and agreed with the electrical conductivity and $\mathrm{pH}$ results in aqueous suspension

Table 5. Fixed $\mathrm{CH}$ percentages for pastes PC/RSA.

\begin{tabular}{ccccc}
\hline & 3 Days & 7 Days & 28 Days & 90 Days \\
\hline PC/RSA 7/3 & $60.9 \%$ & $64.8 \%$ & $81.5 \%$ & $90.7 \%$ \\
PC/RSA 7.5/2.5 & n.d & $62.1 \%$ & $69.5 \%$ & n.d \\
PC/RSA 8/2 & n.d & $59.2 \%$ & $61.1 \%$ & n.d \\
PC/RSA 8.5/1.5 & $37.8 \%$ & $45.1 \%$ & $49.8 \%$ & $55.7 \%$ \\
\hline
\end{tabular}

When comparing RSA reactivity with the reported RHA values, the reactivity found in these pastes for RSA was greater than for RHA. Tashima et al. [37] obtained fixed $\mathrm{CH}$ a percentage of $32 \%$ at 28 days for a $15 \%$ replacement paste for RHA, and other authors have obtained similar values [38]. Therefore, we conclude that despite having a lower silica content, RSA yielded good pozzolanic behavior.

\subsubsection{Mechanical Studies about Mortars}

The mechanical behavior values, obtained for the different analyzed PC/RSA mortars, are represented in Figure 12. 


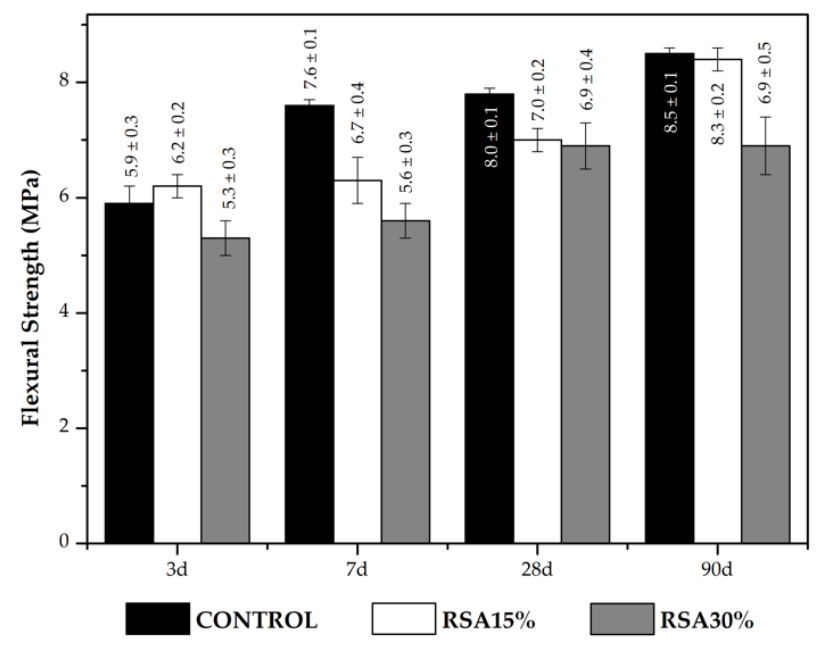

Figure 12. Flexural strength of the analyzed PC/RSA mortars after 3, 7, 28 and 90 days.

For flexural strength (Figure 12), the mortars with 15\% RSA yielded similar strengths to those of the control mortar, while the mortars with $30 \%$ RSA slightly decreased. Usually, the flexural strength values of mortars show more dispersion and relatively high standard deviation values. As expected, by substituting part of PC with RSA, similar or lower strengths are obtained, because the reduction in the amount of hydrates, formed by hydration of PC, is not completely compensated by the pozzolanic reaction products. This is why the flexural strengths for the $30 \%$ RSA replacement mortars were slightly lower than those for the $15 \%$ RSA replacement mortars

To assess the contribution of pozzolanic material to developed strength, the strength activity index (SAI) was calculated following UNE-EN-450-1 [30]. The obtained results are shown in Table 6 . With both the $15 \%$ and 30\% replacements, the SAI yielded values close to $100 \%$ after 3 curing days, which indicates good pozzolanic behavior for RSA. After 90 days, values exceeded $100 \%$. Similar behavior appeared after analyzing other ashes with good resistant activity, such as FA [39].

Table 6. Strength activity index of the mortar with RSA.

\begin{tabular}{ccc}
\hline AGE (Days) & RSA 15\% & RSA $\mathbf{3 0} \%$ \\
\hline $\mathbf{3}$ & 97.45 & 80.79 \\
$\mathbf{7}$ & 98.16 & 83.41 \\
$\mathbf{2 8}$ & 105.97 & 93.15 \\
$\mathbf{9 0}$ & 108.95 & 107.54 \\
\hline
\end{tabular}

The compressive strength values are shown in Figure 13. It is noteworthy that the $15 \%$ and $30 \%$ replacements did not bring about a marked reduction in strength: for the $15 \%$ replacement series, compressive strength after 28 days was greater than that for the control mortar, whereas this behavior appeared after 90 curing days for the $30 \%$ series. In the same way that has been explained for the flexural strength, in the compressive strength we find lower values for the mixture with 30\% RSA with respect to the mixture with 15\% RSA. To assess the contribution of RSA to compressive strength evolution, fitting strength vs. curing time was carried out. The curve followed a logarithmic trend (Equation (5)):

$$
R c=\alpha+\beta \ln (t)
$$




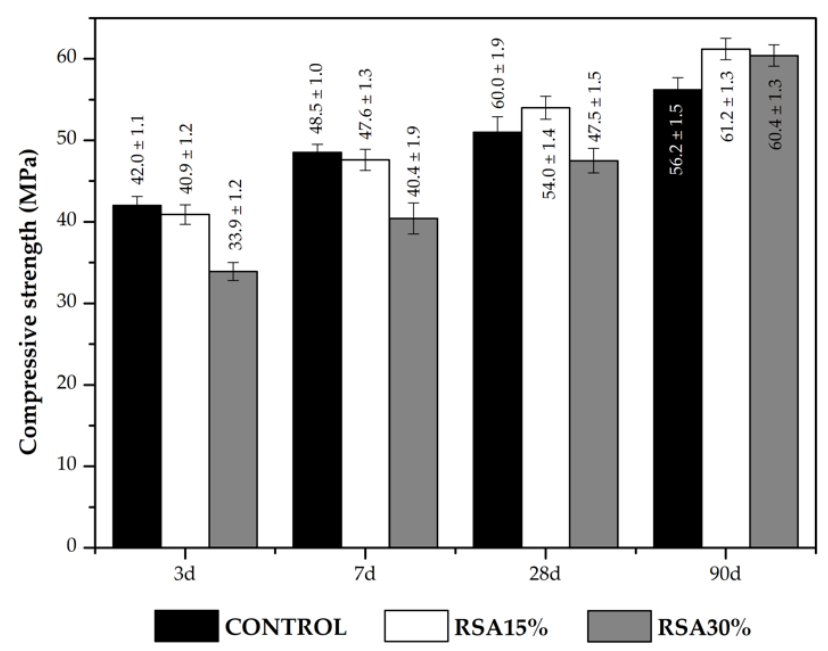

Figure 13. Compressive strength of the control and PC/RSA mortars versus curing time.

Figure 13 represents compressive strength evolution versus curing time. The adjustment parameters are shown in Table 7.

Table 7. Parameters from the compressive strength fitting.

\begin{tabular}{cccc}
\hline Mortar & $\boldsymbol{\alpha}$ & $\boldsymbol{\beta}$ & $\mathbf{R}^{\mathbf{2}}$ \\
\hline Control & 39.20 & 3.72 & 0.94 \\
RSA 15\% & 35.48 & 5.64 & 0.99 \\
RSA $\mathbf{3 0} \%$ & 25.54 & 7.31 & 0.98 \\
\hline
\end{tabular}

As seen in Table 7, the $\alpha$ values are lower for the mortar control, which causes the curve to move vertically downward, which indicates lower compression strength values at an early age. Thus, for short curing ages, the contribution of pozzolan to strength did not compensate the PC replacement with RSA. Moreover, the $\beta$ parameter increased in relation to the control, which indicates a significant contribution of the pozzolanic reaction with curing time, especially for the system with the 30\% replacement. This confirms the mid- to long-term effect of RSA as pozzolanic material.

\section{Conclusions}

The main conclusions drawn from this research are:

- Chemical composition shows silica content to be about $52 \%$, with high percentages of potassium oxide $(12 \%)$ and chloride $(3.5 \%)$. These chlorides can be reduced by washing the sample with hot water.

- The analysis of crystalline and amorphous silica indicates that RSA is mainly of an amorphous nature.

- $\quad$ A positive result is obtained in the Frattini test, and the $\mathrm{pH}$ and electrical conductivity behavior of the $\mathrm{CH}$ /ash suspensions demonstrated that RSA is considered a lowactivity pozzolan. When RSA is washed, greater ash reactivity takes place, which is classified as a medium-reactivity pozzolan.

- $\quad$ The thermogravimetric analysis showed marked RSA reactivity, and high $\mathrm{CH}$ fixation values were obtained in the $\mathrm{CH}$ and cement pastes with RSA.

- In mechanical strength terms, good pozzolanic reactivity was found, along with major contribution to compressive strength for the 28-90 day period.

- $\quad$ RSA can be used as a pozzolanic material and is a good option for valorizing the resulting ash after biomass combustion. Only the high chloride content should be taken into account for use in applications in which the content of this chemical parameter is limited (e.g., steel-reinforced concrete or pre-stressed concrete). The use of RSA would not be considered in the EHE-08 standard. 
- Using this type of cement containing RSA, precast concrete elements such as blocks, bricks, tubes, pavements and tiles, without steel reinforcement could be manufactured.

Author Contributions: S.H. performed much of the experimental section of this work. L.S. and A.F. contributed to the thermogravimetric, the mechanical and the FESEM tests. Furthermore, they were involved in the writing: the manuscript preparation, review and editing. J.P. and J.M. supported the research planning, and the manuscript writing and review. M.V.B. was the director of the investigation. She identified the DRX patterns and wrote the original draft, and reviewed and edited the manuscript. All authors have read and agreed to the published version of the manuscript.

Funding: This research was funded by the Spanish Government and FEDER funds (MINECO/FEDERProject RTI2018-09612-B-C21).

Institutional Review Board Statement: Not applicable.

Informed Consent Statement: Not applicable.

Data Availability Statement: Not applicable.

Acknowledgments: The authors would like to thank the Electronic Microscopy Service at the UPV.

Conflicts of Interest: The authors declares no conflict of interest.

\section{References}

1. Thomas, M.; Barcelo, L.; Blair, B.; Cail, K.; Delagrave, A.; Kazanis, K. Lowering the carbon footprint of concrete by reducing clinker content of cement. Trans. Res. Rec. 2012, 2290, 99-104. [CrossRef]

2. Proaño, L.; Sarmiento, A.T.; Figueredo, M.; Cobo, M. Techno-economic evaluation of indirect carbonation for $\mathrm{CO}_{2}$ emissions capture in cement industry: A system dynamic approach. J. Clean. Prod. 2020, 263, 121457.

3. Celik, K.; Meral, C.; Gursel, A.P.; Mehta, P.K.; Horvath, A.; Monteiro, P.J.M. Mechanical properties, durability, and life-cycle assessment of self-consolidating concrete mixtures made with blended Portland cements containing fly ash and limestone powder. Cem. Concr. Compos. 2015, 56, 59-72. [CrossRef]

4. Schöler, A.; Lothenbach, B.; Winnefeld, F.; Zajac, M. Hydration of quaternary Portland cement blends containing blast-furnace slag, siliceous fly ash and limestone powder. Cem. Concr. Compos. 2015, 55, 374-382. [CrossRef]

5. Abd Elaty, M.A.A.; Ghazy, M.F. Performance of Portland cement mixes containing silica fume and mixed with lime-water. HBRC J. 2014, 10, 247-257. [CrossRef]

6. Radlinski, M.; Olek, J. Investigation into the synergistic effects in ternary cementitious systems containing Portland cement, fly ash and silica fume. Cem. Concr. Compos. 2012, 34, 451-459. [CrossRef]

7. Langan, B.W.; Weng, K.; Ward, M.A. Effect of silica fume and fly ash on heat of hydration of Portland cement. Cem. Concr. Res. 2002, 32, 1045-1051. [CrossRef]

8. Nunes, L.R.J.; Loureiro, L.M.E.F.; Sa, L.C.R.; Silva, H.F.C. Evaluation of the potential for energy recovery from olive oil industry waste: Thermochemical conversion technologies as fuel improvement methods. Fuel 2020, 279, 118536.

9. Reid, W.V.; Ali, M.K.; Field, C.B. The future of bioenergy. Glob. Chang. Biol. 2020, 26, 274-286. [CrossRef]

10. Dong, L.; Wu, X.; Wang, Q.; Cao, G.; Zhou, C.; Ren, N. Evaluation of a novel pretreatment of NaOH/Urea at outdoor cold-winter conditions for enhanced enzymatic conversion and hythane production from rice straw. Sci. Total Environ. 2020, 744, 140900. [CrossRef]

11. Ribó, M.; Albiach, R.; Pomares, F.; Canet, R. Alternativas de Gestión de la Paja de Arroz en la Albufera de València; Instituto Valencia de Investigaciones Agrarias (IVIA): Generalitat Valenciana, Valencia, 2017. (In Spanish)

12. Martirena, F.; Monzó, J. Vegetable ashes as supplementary cementitious materials. Cem. Concr. Res. 2018, 114, 57-64. [CrossRef]

13. Ahsan, M.B.; Hossain, Z. Supplemental use of rice husk ash (RHA) as a cementitious material in concrete industry. Constr. Build. Mater. 2018, 178, 1-9. [CrossRef]

14. Joshaghani, A.; Moeini, M.A. Evaluating the effects of sugarcane-bagasse as and rice-husk ash on the mechanical and durability properties of mortar. J. Mater. Civ. Eng. 2018, 30, 04018144. [CrossRef]

15. Adesina, P.; Olutoge, F.A. Structural properties of sustainable concrete developed using rice husk ash and hydrated lime. J. Build. Eng. 2019, 25, 100804. [CrossRef]

16. Kang, S.H.; Hong, S.G.; Moon, J. The use of rice husk ash as reactive filler in ultra-high performance concrete. Cem. Concr. Res. 2019, 115, 389-400. [CrossRef]

17. Miller, S.A.; Cunningham, P.R.; Harvey, J. Rice-based ash in concrete: A review of past work and potential environmental sustainability. Resour. Conserv. Recycl. 2019, 146, 416-430. [CrossRef]

18. Roselló, J.; Soriano, L.; Santamarina, M.P.; Akasaki, J.L.; Monzó, J.; Payá, J. Rice straw ash A potential pozzolanic supplementary material for cementing systems. Ind. Crops Prod. 2017, 103, 39-50. [CrossRef] 
19. Sung, C.Y.; Lee, H.M.; Kim, Y.I.; Kim, K.-T.; Seo, D.S.; Nam, K.S. Engineering properties of concrete with rice straw ash. J. Agric. Sci. Technol. 1998, 25, 285-292.

20. Munshi, S.; Dey, G.; Sharma, R.P. Use of rice straw ash as pozzolanic material in cement mortar. Int. J. Eng. Technol. 2013, 5, 603-606. [CrossRef]

21. Munshi, S.; Sharma, R.P. Experimental investigation on strength and water permeability of mortar incorporate with rice straw ash. Adv. Mater. Sci. Eng. 2016, 3, 9696505. [CrossRef]

22. Munshi, S.; Sharma, R.P. Investigation on the pozzolanic properties of rice straw ash prepared at different temperatures. Mater. Express 2018, 8, 157-164. [CrossRef]

23. Agwa, I.S.; Omar, O.M.; Tayeh, B.A.; Abdelsalam, B.A. Effects of using rice straw and cotton stalk ashes on the properties of lightweight self-compacting concrete. Constr. Build. Mater. 2020, 235, 117541. [CrossRef]

24. Pandey, A.; Kumar, B. Effects of rice straw ash and micro silica on mechanical properties of pavement quality concrete. J. Build. Eng. 2019, 26, 100889. [CrossRef]

25. Bouzón, N. Activadores Alcalinos Alternativos a Partir de la Ceniza de Cáscara de Arroz Para la Fabricación de Geopolímeros Ph.D. Thesis, Universitat Politécnica de Valéncia, València, Spain, 2015. (In Spanish).

26. Tashima, M.M.; Soriano, L.; Borrachero, M.V.; Akasaki, J.L.; Payá, J. New method to assess the pozzolanic reactivity of mineral admixtures by means of $\mathrm{pH}$ and conductivity measurements in lime: Pozzolan suspensions. Mater. Constr. 2014, 64, e032.

27. UNE-EN 196-5. Methods of Testing Cement-Part 5: Pozzolanicity Test for Pozzolanic Cement; AENOR: 2011. Available online: https:/ / infostore.saiglobal.com/preview/is/en/2011/i.s.en196-5-2011.pdf?sku=1461445 (accessed on 15 November 2020).

28. Donatello, S.; Tyrer, M.; Cheeseman, C.R. Comparison of Test Methods to Assess Pozzolanic Activity. Cem. Concr. Compos. 2010, 32, 121-127. [CrossRef]

29. Payá, J.; Monzó, J.; Borrachero, M.V. Fluid catalytic cracking catalyst residue (FC3R): An excellent mineral by-product for improving early-strength development of cement mixtures. Cem. Concr. Res. 1999, 29, 1773-1779. [CrossRef]

30. UNE-EN 450-1. Fly Ash for Concrete-Part 1: Definition, Specifications and Conformity Criteria; AENOR: Madrid, Spain, 2013; Available online: https: / infostore.saiglobal.com/preview /98701122690.pdf?sku=871436_SAIG_NSAI_NSAI_20720611461445 (accessed on 15 November 2020).

31. Kubiliute, R.; Kaminskas, R.; Kazlauskaite, A. Mineral wool production waste as an additive for Portland cement. Cem. Concr. Compos. 2018, 88, 130-138. [CrossRef]

32. Chen, X.; Bi, Y.; Zhang, H.; Wang, J. Chlorides removal and control though water-washing process on MSWI fly ash. Procedia Environ. Sci. 2016, 31, 560-566. [CrossRef]

33. Moraes, M.J.B.; Moraes, J.C.B.; Tashima, M.M.; Akasaki, J.L.; Soriano, 1.; Borrachero, M.V.; Payá, J. Production of bamboo leaf ash by auto-combustion for pozzolanic and sustainable use in cementitious matrices. Constr. Build. Mater. 2019, 208, 369-380. [CrossRef]

34. Cordeiro, G.C.; Toledo Filho, R.D.; De Moraes Rego Fairbairn, E. Use of ultrafine rice husk ash with high-carbon content as pozzolan in high performance concrete. Mater. Struct. 2009, 42, 983-992. [CrossRef]

35. Payá, J.; Monzó, J.; Borrachero, M.V.; Velázquez, S. Chemical activation of pozzolanic reaction of fluid catalytic cracking catalyst residue (FC3R) in lime pastes: Thermal analysis. Adv. Cem. Res. 2004, 16, 123-130. [CrossRef]

36. Payá, J.; Monzó, J.; Borrachero, M.V.; Velázquez, S. Evaluation of the pozzolanic activity of fluid catalytic cracking catalyst residue (FC3R). Thermogravimetric analysis studies on FC3R-Portland cement pastes. Cem. Concr. Res. 2003, 33, 603-609. [CrossRef]

37. Tashima, M.M.; Fioriti, C.F.; Akasaki, J.L.; Payá, J.; Sousa, L.C.; Melges, J.L.P. High reactive rice husk ash (RHA): Production method and pozzolanic reactivity. Ambiente Construido 2012, 12, 151-163. [CrossRef]

38. Xu, W.; Yiu Lo, T.; Wang, W.; Ouyang, D.; Wang, P.; Xing, F. Pozzolanic reactivity of silica fume and ground rice husk ash as reactive silica in a cementitious system: A comparative study. Materials 2016, 9, 146. [CrossRef]

39. Kramar, S.; Ducman, V. Evaluation of ash pozzolanic activity by means of the strength activity index, Frattini test and DTA/TG analysis. Tech. Gaz. 2018, 25, 1746-1752. 